\title{
Design and Analysis of Triple-Band Multi Slotted Microstrip Patch Antenna
}

\author{
Beena $^{1}$, Munna Singh Kushwaha ${ }^{2}$, Paritosh kumar $^{3}$, Amit Kumar Gupta $^{4}$, \\ R. K. Prasad ${ }^{5}$, \\ ${ }^{12345}$ Department of Electronics and Communication EngineeringMadan Mohan Malaviya Engineering College, \\ Gorakhpur, India
}

\begin{abstract}
In this paper, a multi slotted microstrip patch antenna design has been proposed. The characteristics of the antenna are obtained in terms of return loss, gain and bandwidth. It is observed that the new proposed configuration can operate in three different frequency bands with a good amount of bandwidth i.e. bandwidth of $21.12 \%$ at $1.1 \mathrm{GHz}$ frequency band, bandwidth of $11.65 \%$ at $2.11 \mathrm{GHz}$ and bandwidth of $13.05 \%$ at $2.76 \mathrm{GHz}$ frequency band. The resonating behavior in different frequency bands makes this antenna structure suitable for different types of applications with an antenna gain of 6.163dBi and antenna efficiency of 86.82\%. The substrate material with relative permittivity of 4.2 and loss tangent of 0.0013 is used in this proposed antenna. The designing and simulation of the antenna structure is done over IE3D simulation software version 15.02.
\end{abstract}

Keywords: Ground plane, Multi slotted, Patch Antenna, Triple band

\section{Introduction}

With the wide spread proliferation of wireless communication technology in recent years, the demand for compact, low profile and broadband antennas has increased significantly. To meet the requirement, the microstrip patch antenna has been proposed because of its low profile, light weight and low cost [1]. However, conventional microstrip patch antenna suffers from very narrow bandwidth, this poses a design challenge for the microstrip antenna designer to meet the broadband techniques [2,3]. There are several well-known methods to increase the bandwidth of patch antennas, such as the use of thick substrate, cutting a resonant slot inside the patch, the use of a low dielectric substrate, multi- resonator stack configurations, the use of various impedance matching and feeding techniques, and the use of slot antenna geometry [4, 6]. A good amount of increment in the performance of the antenna structure is achieved by using these techniques but the application of these antenna structures are limited to be operated in single frequency band. In this paper a multi slotted rectangular shaped patch antenna structure is designed by cutting three slots in a rectangular microstrip patch antenna. The designed antenna structure is further simulated over IE3D version 15.02. First of all its return loss curve is considered, using this curve the bandwidth of the designed antenna is calculated, further the VSWR curve is considered which will help to decide whether this antenna structure can work in the frequency bands shown in the return loss curve. Another important parameter gain is further considered to analyze the antenna gain, further another important parameter i.e. directivity is shown. At last the efficiency is considered which includes the antenna efficiency as well as radiation efficiency. These all results are analyzed in this paper. The coaxial probe feed method is used for feeding.

\section{Antenna Design}

The proposed antenna structure is designed by cutting three slots in the rectangular patch antenna which is shown in fig. 1 . The antenna structure shown in fig. 1 is designed and simulated over IE3D simulation software. The dimensions of the antenna structure are shown in the figure itself along with table 1.

Table 1: Dimensions of antenna structure

\begin{tabular}{|l|l|}
\hline Description & Dimensions(in mm ) \\
\hline Ground plane & $\mathrm{l}=80, \mathrm{w}=95$ \\
\hline Patch & $\mathrm{l}=60, \mathrm{w}=75$ \\
\hline Slot & $\mathrm{l}=20, \mathrm{w}=10$ \\
\hline
\end{tabular}




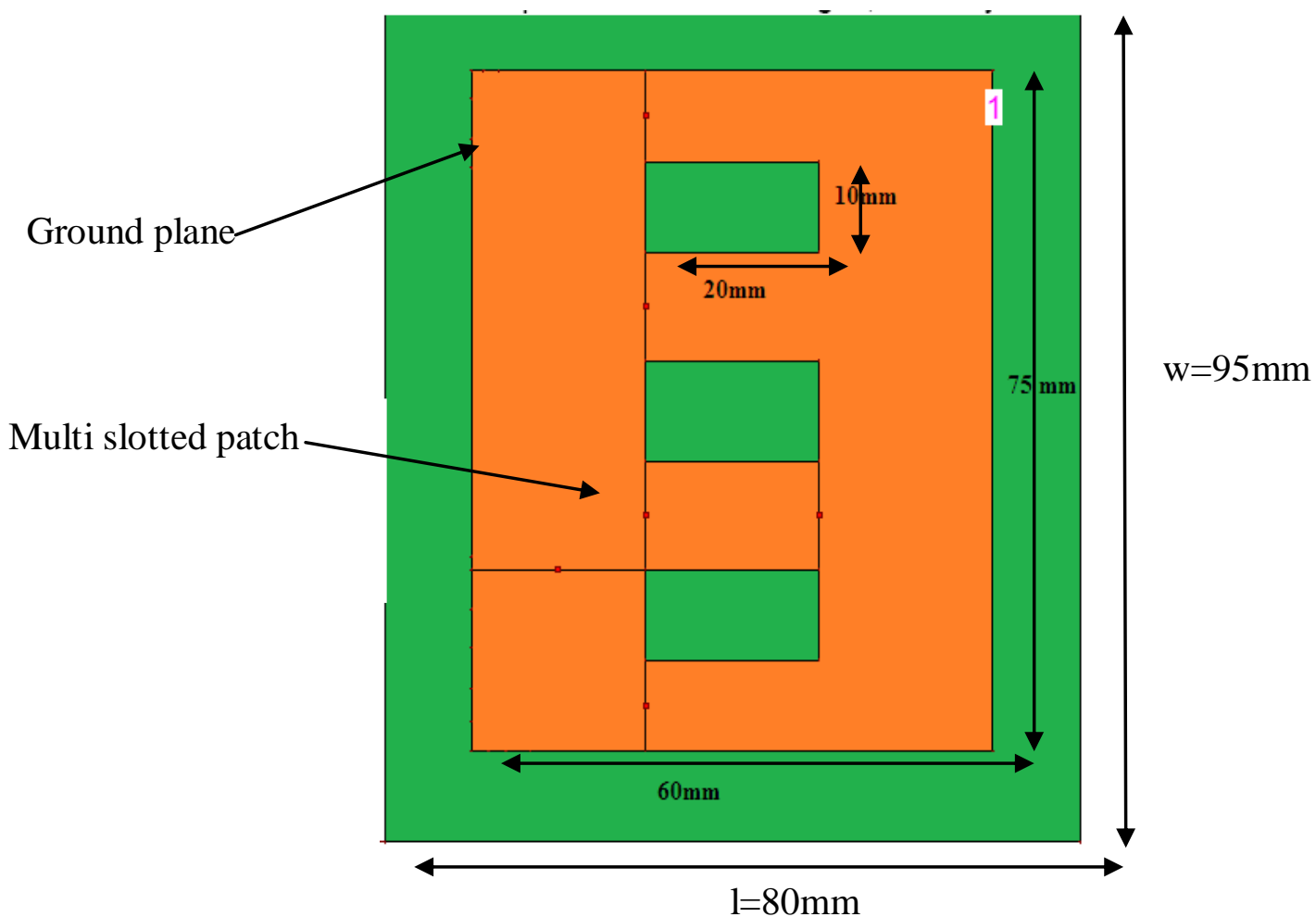

Fig.1 Design of multi slotted Microstrip Patch Antenna

\section{Results And Discussion}

The antenna structure when designed and simulated over IE3D provides good result in terms of bandwidth and makes this antenna well suited to work in three different frequency bands.

\subsection{Return Loss}

The most important parameter to be analyzed is the bandwidth of the antenna and to analyze it the return loss curve is drawn and studied. For any antenna structure with good performance the return loss should be minimum. A standard value of the return loss i.e. $-10 \mathrm{~dB}$ is considered for the calculation of the bandwidth of the antenna structure. The simulation of the antenna structure provides the return loss curve which is shown in fig. 2.

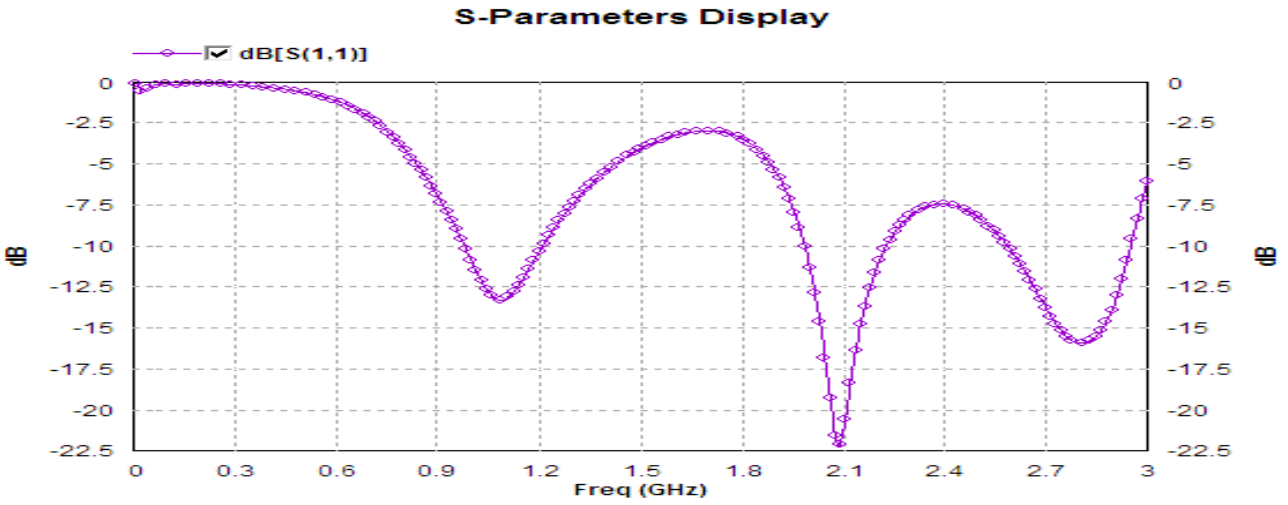

Fig. 2 Return Loss Curve of the Designed Antenna Structure

Calculation of the bandwidth

For frequency band 1

$f_{l l}=0.982 \mathrm{GHz}, f_{h l}=1.214 \mathrm{GHz}, f_{c l}=1.098 \mathrm{GHz}$

Bandwidth $_{1}=\frac{1.214-0.982}{1.098}=\mathbf{2 1 . 1 2 \%}$

For frequency band 2 
$f_{l 2}=1.984 \mathrm{GHz}, f_{h 2}=2.229 \mathrm{GHz}, f_{c 2}=2.107 \mathrm{GHz}$

Bandwidth $_{2}=\frac{2.229-1.984}{2.107}=\mathbf{1 1 . 6 5 \%}$

For frequency band 3

$f_{l 3}=2.584 \mathrm{GHz}, f_{h 3}=2.946 \mathrm{GHz}, f_{c 3}=2.765 \mathrm{GHz}$

Bandwidth $_{3}=\frac{2.946-2.584}{2.765}=\mathbf{1 3 . 0 7 \%}$

The curve shown in fig. 2 and the calculation done shows different amount of bandwidth at different frequency bands i.e. the bandwidth of $21.12 \%, 11.65 \%$ and $13.07 \%$ in different frequency bands which make this antenna structure suitable for three different types of applications.

\subsection{VSWR}

Another very important factor which is related to the bandwidth is the VSWR. The VSWR should be less than 2 in the frequency band in which the antenna has to operate. The VSWR curve of the antenna structure is shown in fig 3.

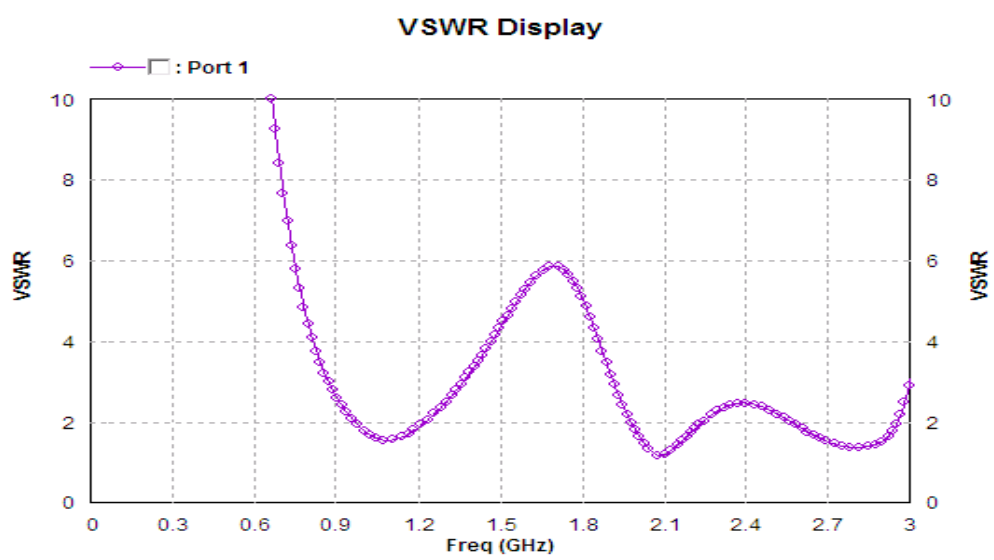

Fig. 3 VSWR Curve

Analyzing the curve shown in fig. 3 it is clearly observed that the VSWR is less than 2 in the frequency bands shown in the return loss curve. Hence this antenna structure can perform well in the above said frequency bands.

\subsection{Gain}

Another important parameter which has to be considered is the gain of the antenna. The total field gain Vs frequency curve is shown in fig. 4.

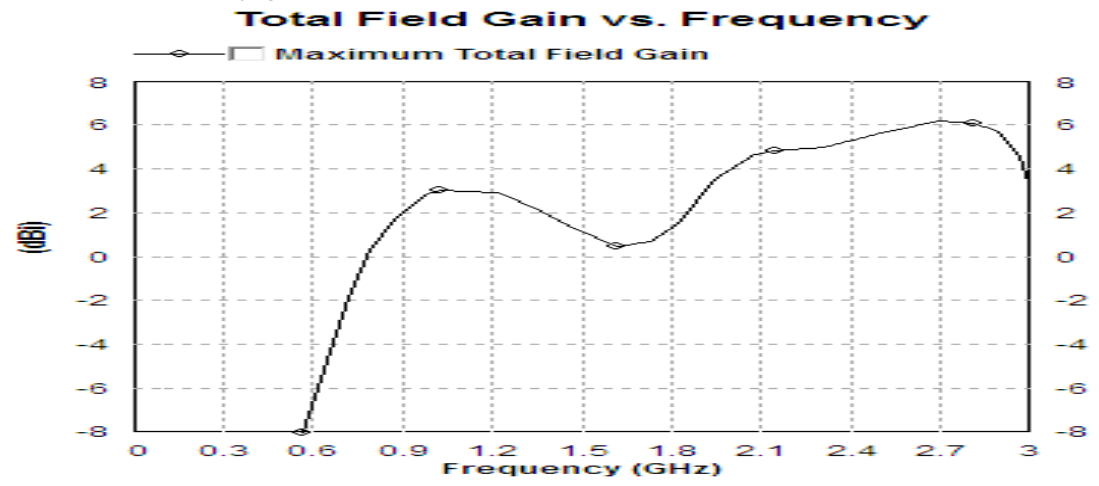

Fig. 4 Total Field Gain Vs Frequency Curve

Analyzing the curve shown in fig. 4 it can be clearly observed that the designed antenna structure provides a good amount of gain i.e. $6.163 \mathrm{dBi}$ which is highly desirable for various applications.

\subsection{Directivity}

Another important parameter which is highly considered is the directivity of the antenna. Fig. 5 shows a curve between Total Field Directivity vs. Frequency 


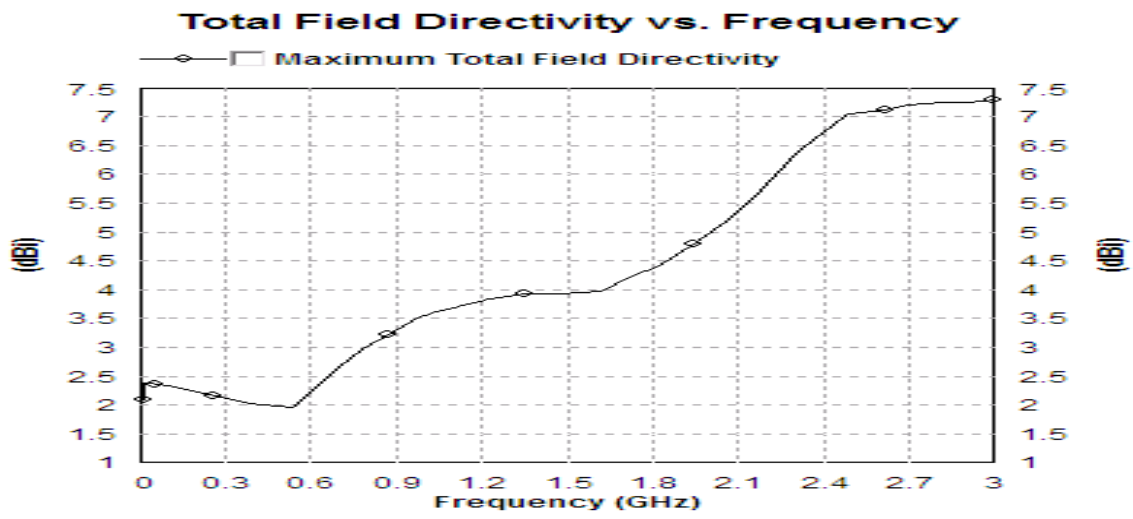

Fig. 5 Total Field Directivity Vs Frequency

Analyzing the curve shown in fig. 5 it can be clearly observed that the designed antenna structure provides good amount of directivity i.e. $7.28 \mathrm{dBi}$ at $2.99 \mathrm{GHz}$ frequency.

\subsection{Antenna efficiency}

Antenna efficiency and radiation efficiency are two important parameters which we have to analyze.

Fig 6 and Fig. 7 shows the antenna efficiency and radiation efficiency respectively

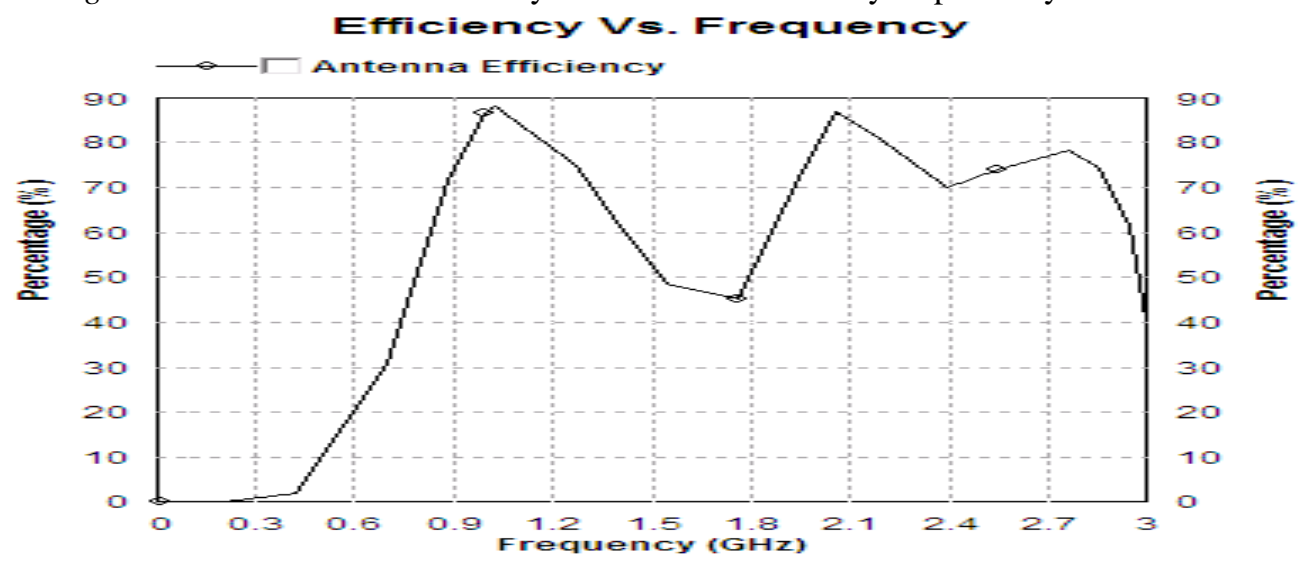

Fig. 6 Antenna Efficiency

Analyzing the antenna efficiency curve we can see antenna efficiency of $86.82 \%$ which quite good while considering the microstrip patch antenna structure.

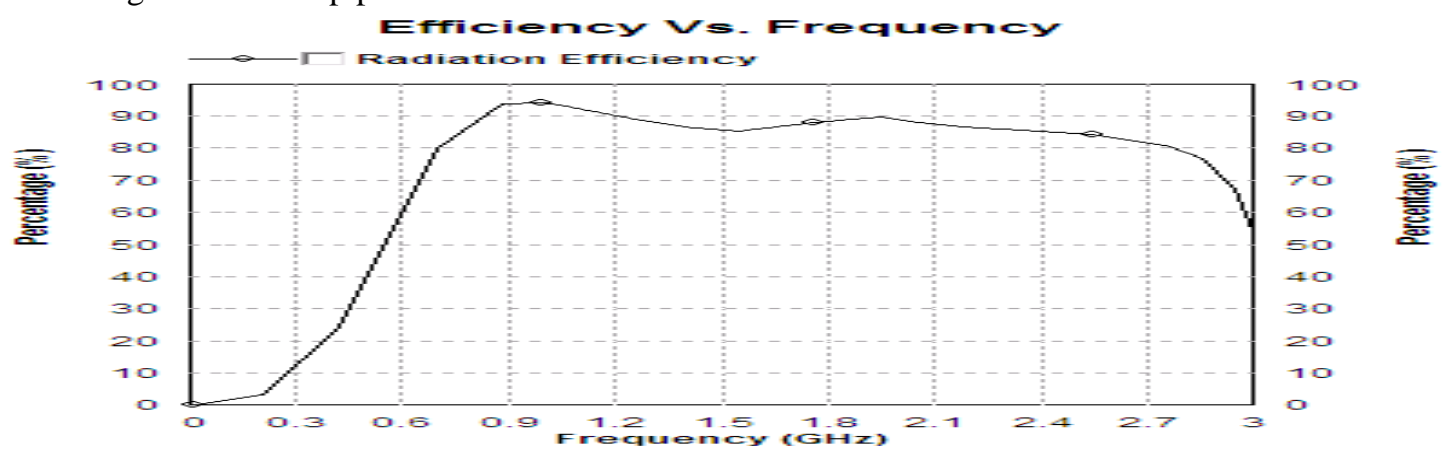

Fig. 7 Radiation Efficiency

\subsection{Radiation efficiency}

Similarly analyzing the radiation efficiency curve we can see a radiation efficiency of $94.34 \%$ which is quite good while considering the microstrip patch antenna structure

\section{Conclusion}

A multi slotted microstrip patch antenna is designed and simulated over IE3D simulation software. The simulation results of this antenna structure is quite good as this antenna structure can work in three different frequency bands with good amount of bandwidth i.e. $21.12 \%, 11.65$ and $13.07 \%$, along with the bandwidth the 
antenna structure also provides good amount of gain i.e. $6.16 \mathrm{dBi}$, directivity of $7.28 \mathrm{dBi}$, antenna efficiency of $86.82 \%$ and radiation efficiency of $94.34 \%$.

\section{Acknowledgement}

The authors would like to express their sincere thanks to Electronics and Communication Engineering Department of M.M.M. Engineering College, Gorakhpur for providing the help to carry out this study and work.

\section{References}

[1]. Yang, S. L. S., A. A. Kishk, and K. F. Lee, IFrequency reconfigurable U-slot microstrip patch antenna," IEEE Antennas Wireless Propag. Lett., Vol. 7, $127\{129,2008$.

[2]. Zhang, Y. P. and J. J. Wang, ITheory and analysis of differentially-driven microstrip antennas," IEEE Trans. Antennas Propag., Vol. $54,1092\{1099,2006$.

[3]. Pozar, D. M. and D. H. Schaubert, Microstrip Antennas: The Analysis and Design of Microstrip Antennas and Arrays, IEEE Press, New York, 1995.

[4]. Matin, M. M., B. S. Sharif, and C. C. Tsimenidis, IProbe fed stacked patch antenna for wideband applications," IEEE Trans. Antennas Propag., Vol. 55, No. 8, 2385\{2388, 2007.

[5]. Wi, S. H., Y. B. Sun, I. S. Song, S. H. Choa, I. S. Koh, Y. S. Lee, and J. G. Yook, LPackage-Level integrated antennas based on LTCC technology," IEEE Trans. Antennas Propag., Vol. 54, No. 8,2190\{2197, 2006.18 Islam, Shakib, and Misran

[6]. Wi, S. H., J. M. Kim, T. H. Yoo, H. J. Lee, J. Y. Park, J. G. Yook, and H. K. Park, IBow-tie-shaped meander slot antenna for 5 GHz application," Proc. IEEE Int. Symp. Antenna Propag., Vol. 2, 456\{459, $2002.897\{901,2007$.

[7]. Ravi Kant, D.C.Dhubkarya, "Design and Analysis of H-Shape Micro strip Patch Antenna", Global Journal of Researches in Engineering, Vol. 10 Issue 6 (Ver 1.0), p.p. 26-29, November 2010.

[8]. Mamdouh Gouda, Mohammed Y. M. Yousef, “A Novel Ultra Wide Band Yagi Micro strip Antenna For Wireless Applications", Journal of Theoretical and Applied Information Technology, p.p. 28-34, 2005 - 2010 JATIT and LLS.

[9]. L. Lolit Kumar Singh, Bhaskar Gupta, Partha P Sarkar, "Compact Circularly Polarized Micro strip Antenna with Slits on both Patch and Ground Plane”, IJECT Vol. 2, Issue 4, p.p. 77-80, ISSN : 2230-7109 (Online),ISSN : 2230-9543 (Print) Oct. - Dec. 2011

[10]. Tiwari, H. Kartikeyan, M.V., "Design Studies Of Stacked U-Slot Micro strip Patch Antenna For Dual Band Operation", Infrared Millimeter and Terahertz Waves (IRMMW-THz), 35th International Conference, p.p. 1 - 2, 5-10 Sept. 2010

[11]. Vinod K. Singh, Zakir Ali, "Dual Band U-Shaped Microstrip Antenna for Wireless Communication", International Journal of Engineering Science and Technology, Vol. 2(6), p.p. 1623-1628, 2010. 